
PERSPECTIVA DO CADE

\author{
Dissertação de Mestrado \\ Orientadora: Professora Dra. Sueli Gandolfi Dallari
}

UNIVERSIDADE DE SÃO PAULO

FACULDADE DE DIREITO

São Paulo - SP

2018 



\title{
A DINÂMICA DO MERCADO DE SAÚDE SUPLEMENTAR SOB A PERSPECTIVA DO CADE
}

\author{
Dissertação de Mestrado apresentada à Banca \\ Examinadora do Programa de Pós-Graduação em \\ Direito, da Faculdade de Direito da Universidade de São \\ Paulo, como exigência parcial para obtenção do título de \\ mestre em Direito, na área de Direitos Humanos, sob a \\ orientação da Professora Dra. Sueli Gandolfi Dallari.
}

UNIVERSIDADE DE SÃO PAULO

FACULDADE DE DIREITO

São Paulo - SP

2018 
Autorizo a reprodução e divulgação total ou parcial deste trabalho, por qualquer meio convencional ou eletrônico, para fins de estudo e pesquisa, desde que citada a fonte.

\section{Serviço de Biblioteca e Documentação}

\section{Faculdade de Direito da Universidade de São Paulo}

Santos, Natali de Vicente
S237d A dinâmica do mercado de saúde suplementar sob a perspectiva do Paulo, Faculdade de Direito, 2018.

$115 \mathrm{f}$.

Orientadora : Professora Dra. Sueli Gandolfi Dallari

Dissertação (Mestrado). Universidade de São Paulo, Programa de Pós-Graduação em Direito, Direitos Humanos, 2018.

1. Direito Antitruste. 2. Saúde Suplementar. 3. CADE. 4. Falhas de mercado. 5. Regra da razão.

I. Dallari, Sueli Gandolfi. II. Título 


\section{FOLHA DE APROVAÇÃO}

SANTOS, Natali de Vicente

Título: A dinâmica do mercado de saúde suplementar sob a perspectiva do CADE

Dissertação de Mestrado apresentada à Banca Examinadora do Programa de Pós-Graduação em Direito, da Faculdade de Direito da Universidade de São Paulo, como exigência parcial para obtenção do título de mestre em Direito, na área de Direitos Humanos, sob a orientação da Professora Dra. Sueli Gandolfi Dallari.

Data:

Banca Examinadora:

Prof. Dr.

Instituição:

Julgamento:

Assinatura:

Prof. Dr.

Instituição:

Julgamento:

Assinatura:

Prof. Dr.

Instituição:

Julgamento:

Assinatura:

Prof. Dr.

Instituição:

Julgamento:

Assinatura: 

Aos meus pais 



\section{AGRADECIMENTOS}

Este trabalho não pôde ser elaborado e tampouco concluído sem o apoio de pessoas a quem serei sempre muito grata.

À Professora Sueli Gandolfi Dallari, pelo trabalho de orientação mesmo antes do meu ingresso no Programa de Pós-Graduação : muito obrigada por todas as valiosas sugestões e ensinamentos desde o primeiro contato. Ainda no contexto da orientação, não posso deixar de prestar meus agradecimentos à Silmara, assistente da Professora Sueli, por todo o auxílio e atenção.

Aos Professores Calixto Salomão Filho e Celso Fernandes Campilongo, pelas importantíssimas críticas e recomendações durante o exame de qualificação, bem como por todas as lições em aula durante a graduação e esta pós-graduação.

Aos queridos Fernanda Duarte Calmon Carvalho, Bruno Droghetti Magalhães Santos, Sara Tironi e Gustavo de Carvalho Marin por me ensinarem o verdadeiro significado de trabalho em equipe. Aos dois últimos agradeço ainda por todas as dicas durante todo o árduo processo de conciliação de atividades acadêmicas e trabalho intenso. Ao Eduardo Molan Gaban, meu agradecimento especial pela parceria profissional nos últimos anos.

Aos amigos superbigodudos e superbigodudas, que são minha família por opção e minha fonte diária de inspiração e orgulho. Em especial, à Maria Cecília de Araujo Asperti e Natalia Felipe Lima Bonfim pelos ouvidos pacientes e palavras sábias em todos os momentos de ansiedade, desespero e alegria durante todas as fases da pós-graduação. Aos queridos amigos (e não menos importantes) Renata Maria Alves, Virgínia e Fabrice Bodinaud, por todo o carinho de sempre e compreensão nos momentos de ausência.

Ao Thiago, pela inabalável paciência e apoio.

Aos meus pais, por tudo. 



\section{RESUMO}

SANTOS, Natali de Vicente. A dinâmica do mercado de saúde suplementar sob a perspectiva do CADE. 115 f. 2018. Dissertação (Mestrado) - Faculdade de Direito, Universidade de São Paulo, São Paulo, 2018.

Esta dissertação de mestrado tem como objetivo avaliar se as falhas de mercado intrínsecas ao mercado de saúde suplementar são consideradas pelo CADE na análise de casos envolvendo o setor. Para esse fim, o primeiro capítulo teve como objeto retomar a finalidade do Direito Antitruste e como ele pode se relacionar com o direito à saúde, que está no pano de fundo do mercado de saúde suplementar. Na sequência, buscou-se analisar, com base da literatura econômica sobre o assunto, a dinâmica do mercado de saúde suplementar, identificando as principais falhas de mercado do setor, bem como possíveis alternativas para mitigar os danos causados por tais características. Ao final, foram analisados precedentes do CADE, buscando-se identificar a metodologia de análise usualmente adotada e a aplicação dos valores que fundamentam a defesa da concorrência.

Palavras-chave : Direito Antitruste; saúde suplementar; falhas de mercado; regra da razão. 



\begin{abstract}
SANTOS, Natali de Vicente. The dynamics of the health insurance market under CADE's perspective. 115 pages. 2018. Dissertation (Masters of Laws) - Faculty of Law, University of São Paulo, São Paulo, 2018.

This dissertation has the purpose to assess whether the market failures that characterize the health insurance market are considered by CADE, the Brazilian antitrust authority, in cases involving the industry. For such an end the first chapter was dedicated to identify the purposes of Antitrust Law and how it s related to the right to health, the grounds for the health insurance market. Based on the economic literature on the subject, the dynamics of the health insurance market was analyzed in order to identify market failures and possible alternatives to mitigate them. Finally, CADE's decisions were analyzed aiming to identify the method adopted by the authority in cases involving health insurance market and the application of competition defense values.
\end{abstract}

Keywords : Antitrust Law, health insurance, market failures, rule of reason. 



\section{SUMÁRIO}

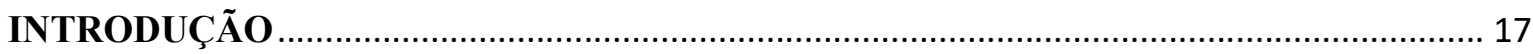

1. A RELAÇÃO ENTRE SAÚDE, DIREITO E ECONOMIA ............................................ 21

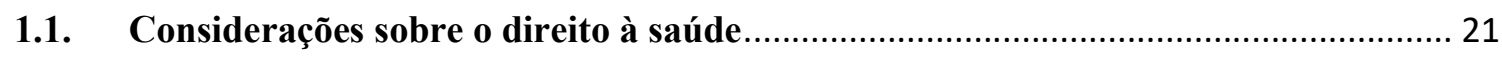

1.1.1. Contextualização: a afirmação histórica do direito à saúde.............................. 21

1.1.2. O direito à saúde na Constituição Federal de 1988 ……................................... 23

1.2. Notas sobre o Direito Antitruste no Brasil.................................................................... 25

1.2.1. Origens e finalidade do Direito Antitruste....................................................... 25

1.2.2. Lei Antitruste no Brasil e atuação do CADE..................................................... 27

1.3. A relação entre a tutela do direito à saúde e Direito Antitruste à luz da teoria dos

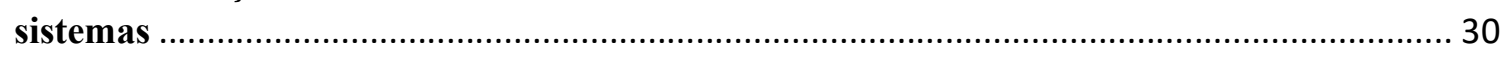

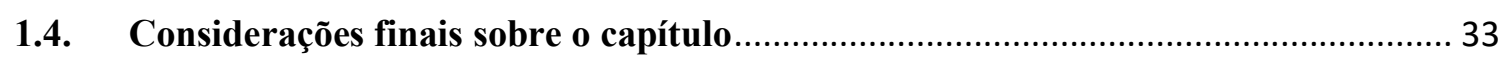

2. A DINÂMICA DO MERCADO DE SAÚDE SUPLEMENTAR ...................................... 35

2.1. As características do mercado de saúde suplementar que o diferenciam do modelo

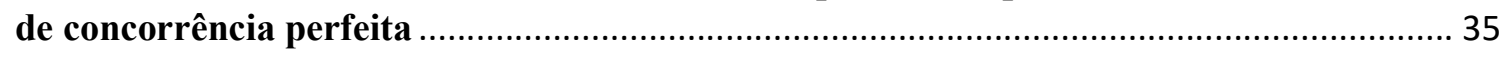

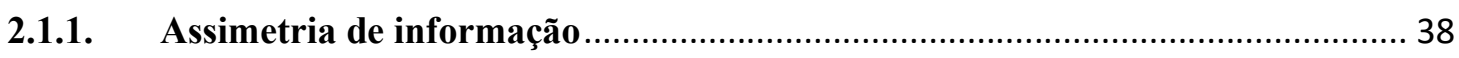

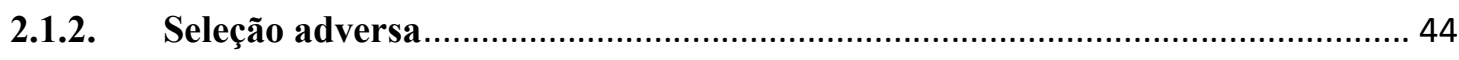

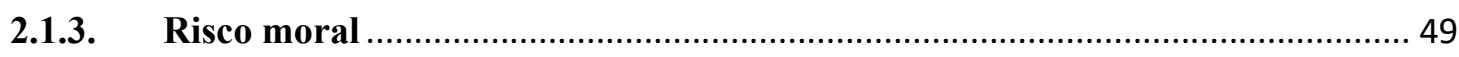

2.2. Outros fatores relevantes para compreender o funcionamento do mercado de saúde

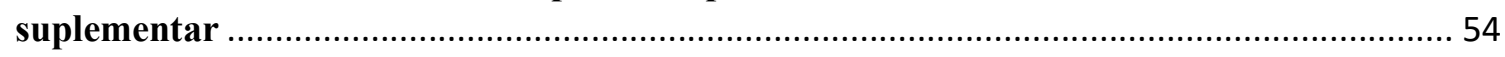

2.3. Justificativa a intervenção estatal no mercado de saúde suplementar ...................... 59

2.3.1. Considerações sobre a regulação estatal ........................................................ 61

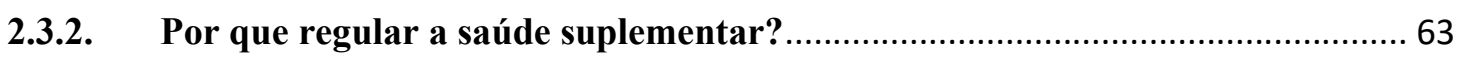

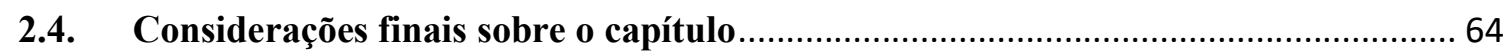

3. PANORAMA SOBRE O MERCADO DE SAÚDE SUPLEMENTAR NO BRASIL ...... 67

3.1. Histórico da regulação do mercado de saúde suplementar no Brasil........................ 67

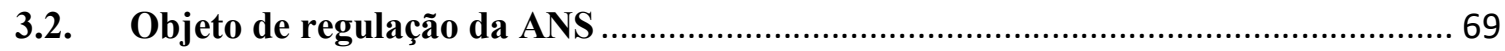

3.3. Dados da ANS sobre a dinâmica do mercado brasileiro de saúde suplementar ....... 72

3.4. O mercado de saúde suplementar à luz de precedentes do CADE ............................ 76

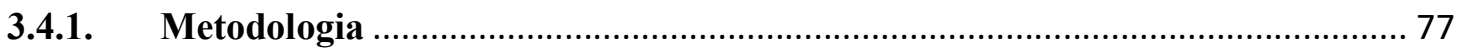

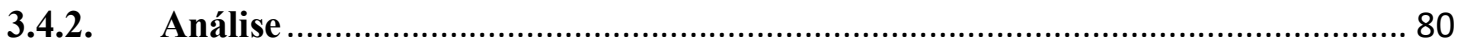

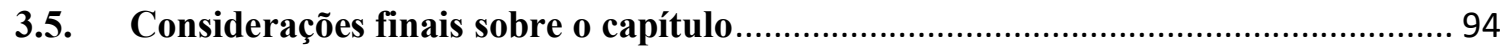

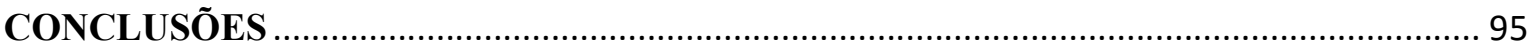

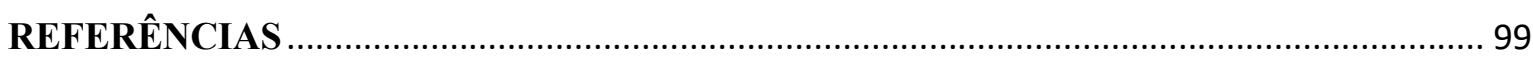

APÊNDICE - LISTA DE DECISÕES ANALISADAS …................................................. 105 


\section{INTRODUÇÃO}

Há inúmeras discussões acerca da (má) qualidade da prestação de serviços à saúde no Brasil, sobretudo no setor de saúde suplementar. A crescente judicialização ${ }^{1}$, bem como a edição de novas regras pela ANS quanto a prazo, tempo e qualidade de atendimento em consultas e procedimentos cobertos por operadoras de planos de $\operatorname{saúde}^{2}$ ou ainda a suspensão da oferta de planos de saúde ${ }^{3}$ evidenciam a má qualidade na prestação de serviços privados de saúde.

Concomitantemente, a discussão sobre o setor de saúde suplementar adquiriu maior destaque também na esfera antitruste com a análise de participações cruzadas entre operadoras de planos de saúde, que justificariam a soma de participações de mercado e a consideração de mais de uma empresa como um único interesse econômico ${ }^{4}$. Essa análise resultou em decisões de veto do Conselho Administrativo de Defesa Econômica - CADE em operações de aquisições de hospitais ou união a outras empresas do setor de saúde suplementar ${ }^{5}$.

De outro lado, no que diz respeito ao controle de condutas, os efeitos deletérios à concorrência decorrentes de tabelas de preços, influência à adoção de conduta comercial uniforme em cooperativas médicas e cláusulas de exclusividade impostas a médicos têm sido

\footnotetext{
1 TReTtel, D. B. Planos de Saúde na visão do STJ e do STF. São Paulo: Verbatim, 2010. Vide também BARROSO, L. R. BARROSO, L. R. Da falta de efetividade à judicialização excessiva: direito à saúde, fornecimento gratuito de medicamentos e parâmetros para a atuação judicial. Estado do Rio de Janeiro, 2008 Disponível em: $<$ http://www.repositorio.furg.br:8080/bitstream/handle/1/3464/La\%20Inalienabilidad\%20de\%20los\%20Dere chos $\% 20$ Humanos. $\% 20 \mathrm{An} \% \mathrm{C} 3 \%$ A 1 lisis $\% 20$ Sistem $\% \mathrm{C} 3 \%$ A 1 tico $\% 20$ sobre $\% 20 \mathrm{e}$

$1 \% 20$ conocido $\% 20$ caso $\% 20 \mathrm{del} \% 20$ lanzamiento $\% 20 \mathrm{de} \% 20$ enanos.pdf? sequence $=1 \#$ page $=89>$. Acesso em: 12.10. 2014.

${ }^{2}$ Resolução Normativa ANS no $259 / 2011$.

3 Por exemplo, <http://www.ans.gov.br/a-ans/sala-de-noticias-ans/consumidor/2575-ans-suspendecomercializacao-de-123-planos-de-28-operadoras>, acesso em 12.10.2014.

4 Nesse sentido, vide, por exemplo, os Atos de Concentração no 08012.009906/2009-17. (Requerentes: Medial Saúde S.A. e Amil Assistência Médica Internacional. Relator: Elvino Carvalho de Mendonça. Julgado em 17.04.2013).

${ }^{5}$ BRASIL. Conselho Administrativo de Defesa Econômica. Atos de Concentração no 08012.006653/2010-55. (Requerentes: Hospital Fluminense S.A e FMG Empreendimentos Hospitalares S.A. Relator: Marcos Paulo Veríssimo. Julgado em 10.10.2012), 08012.010094/2008-63 (Requerentes: Casa de Saúde Santa Lúcia S.A. e Amil Assistência Médica Internacional Ltda. Relator: Elvino de Carvalho Mendonça. Julgado em 29.08.2012), 08700.004150/2012-59 (Requerentes: Hospital Santa Lúcia S.A, Medgrupo Participações S.A e Rede D’Or São Luiz S.A. Relator: Ricardo Machado Ruiz. Julgado em 10.10.2012).
} 
analisados com frequência. A quantidade e relevância dos casos culminaram na elaboração do caderno "Mercado de Saúde Suplementar: Condutas", editado em 2015 pelo CADE6.

Vale dizer, decisões recentes da autoridade antitruste brasileira reconhecem a existência a redução no grau de concorrência dos mercados relacionados à prestação de serviços privados de saúde e os potenciais efeitos nocivos ao consumidor decorrentes das práticas abusivas objeto de condenação e de alguns atos de concentração econômica.

Aliado a isso, verifica-se a crescente verticalização das operadoras de planos de saúde já constatada pela ANS. Hoje, segundo apurado pela agência, ao menos $20 \%$ das operadoras de planos de saúde já possuem estruturas verticalizadas, ou seja, atuam em mais de uma etapa da cadeia de prestação de serviços, possuindo, por exemplo, hospitais ou redes de laboratórios vinculados ${ }^{7}$.

Nesse contexto, é importante lembrar que o Direito Antitruste é matéria interdisciplinar. Ou seja, á área do Direito que envolve não somente institutos e conceitos de áreas diferentes do Direito em sua aplicação, mas também exige a aplicação de conceitos e teorias econômicas para se avaliar adequadamente os impactos concorrenciais de determinadas conduta sobre o funcionamento dos mercados e, especialmente sobre o consumidor. ${ }^{8}$

Diante disso, pretende-se analisar o posicionamento do CADE em suas decisões sobre o setor de saúde suplementar à luz da teoria econômica, com o objetivo de se verificar se os pressupostos teóricos são considerados pelo CADE em suas decisões.

Para tanto, escolheu-se basear-se na posição de AKERLOF (1970), ARROW (1963) e STIGLITZ e ROTHSCHILD (1976), que foram identificados como as principais referências sobre as falhas de mercado que caracterizam o mercado de seguros-saúde, ${ }^{9}$ para

\footnotetext{
6 Disponível em <http://www.cade.gov.br/acesso-a-informacao/publicacoes-institucionais/dee-publicacoesanexos/copy_of_cadernos-do-cade-2013-mercado-de-saude-suplementar-condutas-2013-2015.pdf $>$. Acesso em 03.07.2016.

${ }^{7}$ Fonte:

$<$ http://www.ans.gov.br/images/stories/Materiais_para_pesquisa/Perfil_setor/Foco/foco_marco2014.pdf>, acesso em 12.10.2014.

${ }^{8}$ Nessa linha, vide, por exemplo a constatação feita por KHARMANDAYAN, L. A relação entre Direito e a Teoria Econômica na Jurisprudência do CADE sobre Tabelas Médicas. Dissertação de MestradoBrasília: Universidade de Brasília, 2015.

${ }^{9}$ Os seguros-saúde referidos na literatura sobre o sistema norte-americano são equivalentes aos planos de saúde presentes no mercado brasileiro de saúde suplementar.
} 
desenvolver a dissertação de mestrado. Segundo esses autores, o mercado de seguros é caracterizado por elevado grau de assimetria de informação, que, por sua vez, geraria significativo grau de incerteza à atuação de seguradoras e à demanda dos consumidores pacientes. A partir do quanto defendido por esses autores e, tendo em vista a relação entre Economia e Direito Antitruste, pretende-se analisar decisões do CADE envolvendo o mercado de saúde suplementar, com o objetivo de verificar se as preocupações apontadas por esses autores podem ser identificadas na análise realizada pela autoridade antitruste em casos envolvendo o mercado de saúde suplementar.

Para responder a esse questionamento, o capítulo 1 traz informações que permitem contextualizar a discussão ora proposta. Para tanto, serão abordadas de forma sucinta a tutela do direito à saúde, desde sua afirmação histórica, até a previsão constitucional como direito fundamental no Brasil. Também serão abordadas a origem e finalidade do Direito Antitruste, ressaltando a relevância da relação entre Direito e Economia para esse ramo do direito. Por fim, serão apresentadas algumas considerações sobre a relação entre Direito e Saúde e Direito e Economia como forma de dar elementos que justifiquem a relevância do tema a ser estudado nesta dissertação.

O Capítulo 2 trata da literatura sobre as falhas de mercado que caracterizam o mercado de saúde suplementar. Com base nos textos de de AKERLOF (1970), ARROW (1963) e STIGLITZ e ROTHSCHILD (1976), bem como de outros autores que, em vista das propostas dessas referências, analisaram os impactos da assimetria de informação, risco moral e seleção adversa sobre a dinâmica concorrencial do mercado de saúde suplementar, bem como se debruçaram sobre a identificação de outros fatores que podem contribuir para a tendência ao desequilíbrio competitivo desse mercado. Na mesma seção será abordado o tema da intervenção estatal, em especial a regulação, como forma de mitigação dos efeitos deletérios das falhas de mercado identificadas.

Por fim, o Capítulo 3 tem como objetivo analisar o mercado de saúde suplementar no Brasil. Para tanto, será apresentado um panorama sobre a regulação do setor no País. Na sequência, será explorado o objeto principal deste trabalho: avaliar como o CADE tem decidido em casos envolvendo o mercado de saúde suplementar com a finalidade de identificar se e em que medida as falhas de mercado estudadas no Capítulo 2 são consideradas na análise antitruste da autoridade. 


\section{CONCLUSÕES}

É inegável a relevância e destaque que a saúde suplementar tem adquirido nos últimos tempos em todas as esferas. Do ponto de vista exclusivamente social, a crescente judicialização relacionada a negativas de cobertura, bem como os aumentos significativos dos preços de planos de saúde a cada ano de cerca de $20 \%$, chegando a $60 \%$ quando há alteração para faixa etária correspondente à terceira idade relevam tratar-se de setor tendente ao colapso.

Do ponto de vista econômico e jurídico (mas também do ponto de vista social) a regulação setorial não tem se mostrado suficiente para eliminar os danos causados pelas falhas de mercado que levam à situação da saúde suplementar no Brasil. No mesmo sentido, o número de fusões e aquisições entre operadoras de planos de saúde e movimentos de verticalização por meio de aquisições de hospitais, laboratórios e outras entidades de prestação de serviços de saúde indicam, em conjunto com os outros elementos apontados acima, que o mercado de saúde suplementar no Brasil começa a mostrar os primeiros sinais de declínio.

Esse movimento tendente ao colapso foi descrito por AKERLOF (1970) como resultado do elevado grau de assimetria de informação que permeia o setor. Essa assimetria de informação, por sua vez, gera uma série de incertezas no mercado descritas em detalhes por ARROW (1963). Dentre esses fatores, merecem destaque a seleção adversa (indisponibilidade de planos de saúde para pacientes de mais idade ou saúde mais debilitada, que oferecem mais risco à operadora de plano de saúde em virtude o crescente preço do plano) e o risco moral (aumento da demanda por serviços de saúde em virtude da própria existência de um plano de saúde contratado).

A assimetria de informação, juntamente à seleção adversa e ao risco moral, bem como as elevadas barreiras à entrada características do mercado, a assimetria de informação entre médico e paciente, bem como entre médico e operadora de plano de saúde elevam bastante os custos e os riscos operacionais das operadoras de planos de saúde. Esse aumento de custo, por sua vez, representa um incentivo à concentração do setor nas mãos de operadoras de saúde de maior porte, com maior número de beneficiários. 
Diante desse cenário, buscou-se avaliar a perspectiva do CADE sobre o mercado de saúde suplementar. Essa proposta se justifica não somente pela dinâmica do mercado apontada acima, mas também pelo objetivo intrínseco do Direito Antitruste: buscar o bemestar do consumidor e proteger o mercado dos abusos de poder econômico. Se a literatura econômica é farta ao identificar todas as falhas de mercado da saúde suplementar e propor modelos sob os quais a concorrência no mercado e as condições ofertadas aos pacientes seriam mais positivas, por que não avaliar, do ponto de vista jurídico, especificamente do Direito Antitruste, se essas falhas de mercado também são abordadas pelo CADE na aplicação da Lei Antitruste?

Com esse objetivo, buscou-se, no primeiro capítulo, compreender a relevância do tema do direito à saúde, sobre o qual a saúde suplementar se funda, bem como entender os mecanismos do Direito Antitruste e como esses dois temas podem se mesclar para a análise do objeto deste trabalho. Neste capítulo, foi possível observar que o Direito Antitruste representa a interface entre Direito e Economia, buscando o equilíbrio das relações econômicas por meio de mecanismos jurídicos. A saúde suplementar, por sua vez, mistura o sistema sanitário e economia na formação de um mercado que envolve um direito fundamental, supostamente a ser priorizado sobre os interesses individuais, mas que é sopesado o tempo todo com os mecanismos de livre mercado.

O segundo capítulo teve como propósito explorar a literatura econômica sobre o funcionamento do mercado de saúde suplementar, buscando entender os fatores que contribuem para a verificação da dinâmica do setor verificada no Brasil. Essa dinâmica deveria ser considerada pelo CADE em suas decisões, pois afeta diretamente os incentivos das operadoras de planos de saúde para exercer seu poder econômico.

Por essa razão, o terceiro capítulo teve como objeto analisar decisões recentes do CADE sobre o mercado de saúde suplementar, visando a identificação das falhas de mercado responsáveis pela instabilidade do setor. A conclusão é que a avaliação desses fatores existe, mas ainda é incipiente. A análise das decisões mais recentes proferidas pela autoridade antitruste indica que a análise de critérios jurídicos ainda é predominante. Vale dizer, as decisões baseiam-se, majoritariamente, na constatação formal de fatos que são presumidamente considerados ilícitos antitruste sob a teoria acerca dos efeitos da ação concertada e da exclusividade no mercado. 
No entanto, há poucas decisões em que o CADE avaliou aspectos como a assimetria de informação e barreiras à entrada como aptos a afetar a análise antitruste de casos. A consideração desses aspectos econômicos não implica a mudança do sistema de análise da autoridade antitruste brasileira. Isso significa que o CADE não deixou de configurar infrações à ordem econômica por seu objeto para passar a avaliar eficiência e racionalidade econômica da conduta. Esse método de análise foi aplicado em poucos precedentes, mas o que se verifica é a avaliação dos fatores econômicos foram utilizados como elementos adicionais para subsidiar o julgamento final.

A avaliação das características econômicas do mercado de saúde suplementar representa significativo avanço do posicionamento do CADE sobre o setor. Contudo, essa evolução ainda é pouco representativa e está longe do ideal, dado que o bem-estar do paciente é pouco mencionado (quando o é) nas decisões proferidas pela autoridade antitruste. Com isso, não fica claro se os julgamentos de fato buscam alcançar a verdadeira finalidade da legislação antitruste. 


\section{REFERÊNCIAS}

AGÊNCIA NACIONAL DE SAÚDE SUPLEMENTAR. Dados gerais do setor. Disponível em: <http://www.ans.gov.br/perfil-do-setor/dados-gerais>. Acesso em: 7 jan. 2018a.

AGÊNCIA NACIONAL DE SAÚDE SUPLEMENTAR. Dados consolidados do setor. Disponível em: <http://www.ans.gov.br/perfil-do-setor/dados-e-indicadores-do-setor>. Acesso em: 7 jan. 2018b.

AITH, F. Curso de Direito Sanitário: a proteção do direito à saude no Brasil. São Paulo: Quartier Latin, 2007.

AKERLOF, G. A. The Market for "Lemons": Quality Uncertainty and the Market Mechanism. The Quarterly Journal of Economics, v. 84, n. 3, p. 488-500, 1970.

ALEXY, R. Teoria dos direitos fundamentais. 2a. edição ed. São Paulo: Malheiros, 2012.

ALMEIDA, C. O mercado privado de serviços de saúde no Brasil: panorama atual e tendências da assistência médica suplementar, 1998.

ALMEIDA, S. F. Poder Compensatório e Política de Defesa da Concorrência: Referencial Geral e Aplicação ao Mercado de Saúde Suplementar Brasileiro. Tese de Doutorado-São Paulo: EESP - FGV, 2009.

ARROW, K. J. Uncertainty and The Welfare of Economics of Medical Care. The American Economic Review, p. 941-973, 1963.

AZEVEDO, P. F. DE et al. A cadeia de saúde suplementar no Brasil: avaliação das falhas de mercado e propostas de políticas. São Paulo: Insper - Centro de Estudos em Negócios, maio 2016. Disponível em: <https://www.insper.edu.br/wpcontent/uploads/2016/09/estudo-cadeia-de-saude-suplementar-Brasil.pdf $>$.

BARROSO, L. R. Da falta de efetividade à judicialização excessiva: direito à saúde, fornecimento gratuito de medicamentos e parâmetros para a atuação judicialEstado do Rio de Janeiro, 2008. Disponível em: $<$ http://www.repositorio.furg.br:8080/bitstream/handle/1/3464/La\%20Inalienabilidad\%20d e\%20los\%20Derechos\%20Humanos. \%20An\%C3\%A1lisis\%20Sistem $\%$ C3\%A1tico\%20so bre $\% 20 \mathrm{e}$

$1 \% 20$ conocido $\% 20$ caso $\% 20$ del $\% 20$ lanzamiento $\% 20 \mathrm{de} \% 20$ enanos.pdf? sequence $=1 \#$ page $=$ 89>. Acesso em: 12 out. 2014

BOBBIO, N. A Era dos Direitos. 13 tiragem ed. Rio de Janeiro: Elsevier, 2004. 
BOONE, J. Basic versus Supplementary Health Insurance: Moral Hazard and Adverse Selection. Rochester, NY: Social Science Research Network, 2 set. 2014. Disponível em: $<$ https://papers.ssrn.com/abstract=2505955>. Acesso em: 17 dez. 2017.

BRUNA, S. V. O poder econômico e a conceituação do abuso em seu exercício. São Paulo: Editora Revista dos Tribunais, 1997.

BUCCI, M. P. D. Direito Administrativo e políticas públicas. São Paulo: Saraiva, 2002.

CADE. Mercado de Saúde Suplementar: Condutas. Brasília: CADE, 2015.

CADE. Guia de Análise de Atos de Concentração. Brasília: CADE, jul. 2016.

CARVALHO, V. M.; GODOY, J. P. O juízo de convencimento aplicável à análise de estruturas concorrenciais e a função congnitiva desempenhada pelo direito societário. In: Remédios antitruste. São Paulo: Singular, 2011.

CORREIA, M. O. G.; CRUZ, R. N. Teoria dos Sistemas de Niklas Luhmann e os desafios para a efetivação jurisdicional do direito à saúde em matéria de medicamentos. Revista Eletrônica de Comunicação, Informação e Inovação em Saúde, v. v. 1, n. 2, dez. 2007.

DALLARI, S. G. O direito à saude. Revista de Saúde Pública, v. 22, n. 1, fev. 1988.

DI PIETRO, M. S. Z. Direito Administrativo. São Paulo: Atlas, 2006.

EINAV, L. et al. Selection on Moral Hazard in Health Insurance. Cambridge, Massachusetts: National Bureau of Economic Research, abr. 2011. Disponível em: $<$ http://www.nber.org/papers/w16969>. Acesso em: 3 jan. 2018.

FARNSWORTH, D. Moral Hazard in Health Insurance: Are Consumer-Directed Plans the Answer. Annals of Health Law, v. 15, p. 251-274, 2006.

FORGIONI, P. Direito Antitruste. 2a. edição ed. São Paulo: Revista dos Tribunais, 2005.

GONÇALVES, G. L.; VILLAS BÔAS FILHO, O. Teoria dos sistemas sociais: Direito e sociedade na obra da Niklas Luhmann. São Paulo: Saraiva, 2013.

GREGORI, M. S. Planos de Saúde: A ótica da proteção do consumidor. 3a. edição revista, atualizada e ampliada ed. São Paulo: Revista dos Tribunais, 2011. v. 31

HABERMAS, J. Mudança estrutural da esfera pública: investigações quanto a uma categoria da sociedade burguesa. 2a. edição ed. Rio de Janeiro: Tempo Brasileiro, 2003.

HARVEY, D. Condição pós-moderna. 17a. edição ed. São Paulo: Loyola, 2008.

HEMENWAY, D. Propitious Selection. The Quarterly Journal of Economics, v. 105, n. 4, p. 1063-1069, 1990.

HEMENWAY, D. Propitious Selection in Insurance. Journal of Risk and Uncertainty, v. 5, n. 3, p. 247-251, 1992. 
HOVENKAMP, H. Economics and Federal Antitrust Law. Student Edition ed. St. Paul, Minnesota: West Publishing Co., 1985.

JACK, W. Equilibrium in competitive insurance markets with ex ante adverse selection and ex post moral hazard. Journal of Public Economics, ISPE Special Issue. v. 84, n. 2, p. 251278, 1 maio 2002.

JHA, S.; BAKER, T. The Economics of Health Insurance. Journal of the American College of Radiology, v. 9, n. 12, p. 866-870, 1 dez. 2012.

KEANE, M.; STAVRUNOVA, O. Adverse Selection, Moral Hazard and the Demand for Medigap Insurance: Health, Econometrics and Data Group (HEDG) Working Papers. [s.1.] HEDG, c/o Department of Economics, University of York, jul. 2010. Disponível em: $<$ https://ideas.repec.org/p/yor/hectdg/10-14.html>. Acesso em: 10 dez. 2017.

KHARMANDAYAN, L. A relação entre Direito e a Teoria Econômica na Jurisprudência do CADE sobre Tabelas Médicas. Dissertação de Mestrado-Brasília: Universidade de Brasília, 2015.

LEANDRO, T. Defesa da Concorrência e Saúde Complementar: A Integração Vertical entre Planos de Saúde e Hospitais e seus Efeitos no Mercado. Dissertação de MestradoBrasília: Universidade de Brasília, 2010.

LUHMANN, N. Law as a Social System. Oxford: University Press, 2004.

MACERA, A. P.; SAINTIVE, M. B. O Mercado de Saúde Suplementar no BrasilSecretaria de Acompanhamento Econômico do Ministério da Fazenda, , 2004. Disponível em: <http://www.seae.fazenda.gov.br/central-de-documentos/documentos-detrabalho/documentos-de-trabalho-2004/DT_31.pdf>. Acesso em: 19 nov. 2017

MANKIW, G. Introdução à Economia: Princípios de Micro e Macroeconomia. 2a. edição ed. Rio de Janeiro: Campus, 2001.

MANNING, W. G.; MARQUIS, M. S. Health insurance: the tradeoff between risk pooling and moral hazard. Journal of Health Economics, v. 15, n. 5, p. 609-639, out. 1996.

MARSHALL, A. Principles of Economics. London: Macmillan and Co., 1890.

MILL, J. S. On liberty. Boston: Ticknor and Fields, 1863.

MONTONE, J. Evolução e Desafios da Regulação do Setor de Saúde Suplementar. In: SUBSÍDIOS AO FÓRUM DE SAÚDE SUPLEMENTAR. Ministério da Saúde, 2003.

NEUDECK, W.; PODCZECK, K. Adverse selection and regulation in health insurance markets. Journal of Health Economics, v. 15, n. 4, p. 387-408, ago. 1996.

PAULY, M. V. Overinsurance and Public Provision of Insurance: The Roles of Moral Hazard and Adverse Selection. The Quarterly Journal of Economics, v. 88, n. 1, p. 4462, 1974. 
POWELL, D.; GOLDMAN, D. Disentangling Moral Hazard and Adverse Selection in Private Health Insurance. [s.1.] National Bureau of Economic Research, jan. 2016. Disponível em: <http://www.nber.org/papers/w21858>. Acesso em: 4 jan. 2018.

RAGAZZO, C. E. J.; MACHADO, K. Desafios da análise do CADE no setor de planos de saúdeFundação Getúlio Vargas, , 2011. Disponível em: $<$ https://works.bepress.com/carlos_ragazzo/12/>. Acesso em: 7 jan. 2018

RIBAS, G. F. C. Processo administrativo de investigação de cartel. São Paulo: Singular, 2016.

SALOMÃO FILHO, C. Direito Concorrencial: As condutas. 1a. edição, segunda tiragem ed. São Paulo: Malheiros, 2007.

SARLET, I. W. Algumas considerações em torno do conteúdo, eficácia e efetividade do direito à saúde pela Constituição Federal de 1988. Revista Eletrônica sobre a Reforma do Estado, v. n. 11, nov. 2007.

SCHWARTZ, G. A. D. SCHWARTZ, G. A. D. Tratamento Jurídico do Risco no Direito à Saúde. Porto Alegre: Livraria do Advogado, 2004. Porto Alegre: Livraria do Advogado, 2004.

SILVA, J. A. Curso de direito constitucional positivo. 16a. edição ed. São Paulo: Malheiros, 1999.

STIGLITZ, J. E.; ROTHSCHILD, M. Equilibrium in Competitive Insurance Markets: An Essay on the Economics of Imperfect Information. Quarterly Journal of Economics, v. 90, n. 4, p. 629-649, nov. 1976.

TRETTEL, D. B. Planos de Saúde na visão do STJ e do STF. São Paulo: Verbatim, 2010.

TUMAY, M. Asymmetric Information and Adverse Selection in Insurance Markets: The Problem of Moral Hazard. Yönetim ve Ekonomi, v. 16/1, p. 107-1114, 2009.

VAN DE VEN, W. P. M. M.; VAN VLIET, R. J. A. Consumer information surplus and adverse selection in competitive health insurance markets: An empirical study. Journal of Health Economics, v. 14, n. 2, p. 149-169, 1995.

VIANNA, C. M. DE M. O Impacto das Ações da ANS no Mercado Operador. Regulação e Saúde vol. 3: Documentos Técnicos de apoio ao Fórum de Saúde Suplementar de 2003, v. Tomo 1, 2004.

VISCUSI, W. K.; HARRINGTON, JR., J. E.; VERNON, J. M. Economics of Regulation and Antitrust. 4. ed. Cambridge, Massachusetts: MIT Press, 2005.

VORONKOFF, I. O novo sistema brasileiro de defesa da concorrência: estrutura administrativa e análise prévia dos atos de concentração. RDC, v. v.2, n. 2, nov. 2014. 
WHISH, R.; BAILEY, D. Competition Law. Seventh Edition ed. Oxford: University Press, 2012. 


\section{APÊNDICE - LISTA DE DECISÕES ANALISADAS}

\begin{tabular}{|c|c|c|c|}
\hline \multicolumn{4}{|c|}{ Ato de Concentração } \\
\hline Número do processo & Partes & Data de Julgamento & Resultado \\
\hline $08700.002372 / 2014-07$ & $\begin{array}{c}\text { Cromossomo Participações II } \\
\text { S.A. e Diagnósticos da América } \\
\text { S.A. ("DASA"). }\end{array}$ & 16.07 .2014 & $\begin{array}{c}\text { Aprovação condicionada à } \\
\text { celebração de acordo. }\end{array}$ \\
\hline
\end{tabular}

\begin{tabular}{|c|c|c|c|c|c|}
\hline \multicolumn{6}{|c|}{ Processos Administrativos } \\
\hline Processo & Representante & Representados & Objeto & Data do julgamento & Decisão \\
\hline 08012.002874/2004-14 & $\begin{array}{l}\text { União Nacional das } \\
\text { Instituições de Auto } \\
\text { Gestão em Saúde - } \\
\text { UNIDAS }\end{array}$ & $\begin{array}{l}\text { Associação Médica da } \\
\text { Grande Dourado - } \\
\text { AMGD, Conselho } \\
\text { Regional de Medicina } \\
\text { do Mato Grosso do Sul - } \\
\text { CRM/MS, União } \\
\text { Nacional das } \\
\text { Instituições de Auto } \\
\text { Gestão em Saúde } \\
\text { - UNIDAS e Dr. } \\
\text { Antonio Fernando } \\
\text { Gaiga }\end{array}$ & $\begin{array}{c}\text { Tabela } \\
\text { médica. Paralisação e } \\
\text { ameaça de } \\
\text { descredenciamento } \\
\text { coletivo. Negociação } \\
\text { Coletiva. }\end{array}$ & $07 / 02 / 2017$ & Condenação \\
\hline
\end{tabular}




\begin{tabular}{|c|c|c|c|c|c|}
\hline \multicolumn{6}{|c|}{ Processos Administrativos } \\
\hline Processo & Representante & Representados & Objeto & Data do julgamento & Decisão \\
\hline 08012.003422/2004-41 & $\begin{array}{l}\text { GEAP-Fundação de } \\
\text { Seguridade Social }\end{array}$ & $\begin{array}{c}\text { Cooperativa dos } \\
\text { Médicos } \\
\text { Anestesiologistas do } \\
\text { Estado do Mato Grosso } \\
\text { - COOPANEST-MT e } \\
\text { União Nacional das } \\
\text { Instituições de } \\
\text { Autogestão em Saúde - } \\
\text { UNIDAS. }\end{array}$ & $\begin{array}{c}\text { Tabela } \\
\text { médica. Paralisação e } \\
\text { ameaça de } \\
\text { descredenciamento } \\
\text { coletivo. Negociação } \\
\text { Coletiva. }\end{array}$ & $18 / 01 / 2017$ & Condenação \\
\hline 08012.009606/2011-44 & $\begin{array}{c}\text { Procuradoria da } \\
\text { República em Campinas } \\
\text { - MPF/SP. }\end{array}$ & $\begin{array}{c}\text { Clínica de Oncologia } \\
\text { Diagnose e Terapia S/C } \\
\text { LTDA. - } \\
\text { ONCOCAMP, Instituto } \\
\text { de Oncologia Clínica } \\
\text { S/S Ltda. - IOC, } \\
\text { Instituto } \\
\text { do Radium de Campinas } \\
\text { Ltda., Oncologia Clínica } \\
\text { de Campinas } \\
\text { S/C Ltda. - OCC, } \\
\text { Oncologia e } \\
\text { Hematologia de } \\
\text { Campinas S/C Ltda. }\end{array}$ & $\begin{array}{c}\text { Cartel para negociação } \\
\text { coletiva. }\end{array}$ & $05 / 09 / 2016$ & Condenação \\
\hline $08012.013467 / 2007-77$ & $\begin{array}{l}\text { Público Federal - } \\
\text { Procuradoria da } \\
\text { República no } \\
\text { Amazonas. }\end{array}$ & $\begin{array}{c}\text { Cooperativa dos } \\
\text { Médicos } \\
\text { Anestesiologistas do } \\
\text { Estado do Amazonas - } \\
\text { COOPANEST-AM e } \\
\text { União Nacional das } \\
\text { Instituições de }\end{array}$ & $\begin{array}{c}\text { Imposição da } \\
\text { Classificação Brasileira } \\
\text { Hierarquizada de } \\
\text { Procedimentos Médicos } \\
\text { (CBHPM). }\end{array}$ & $22 / 03 / 2016$ & Arquivamento \\
\hline
\end{tabular}




\begin{tabular}{|c|c|c|c|c|c|}
\hline \multicolumn{6}{|c|}{ Processos Administrativos } \\
\hline Processo & Representante & Representados & Objeto & Data do julgamento & Decisão \\
\hline & & $\begin{array}{l}\text { Autogestão em Saúde - } \\
\text { UNIDAS. }\end{array}$ & & & \\
\hline 08700.001830/2014-82 & CADE Ex-Ofício & $\begin{array}{c}\text { Federação Brasileira de } \\
\text { Cooperativas de } \\
\text { Anestesiologia - } \\
\text { Febracan, Sociedade } \\
\text { Brasileira de } \\
\text { anestesiologia - SBA, e } \\
\text { Jurandir Coan Turazzi. }\end{array}$ & Cartel & $22 / 03 / 2016$ & Condenação \\
\hline 08012.009381/2006-69 & $\begin{array}{l}\text { Caixa de Assistência } \\
\text { dos Advogados do } \\
\text { Estado } \\
\text { do Rio de Janeiro - } \\
\text { CAARJ }\end{array}$ & $\begin{array}{l}\text { Conselho Regional de } \\
\text { Medicina do Estado do } \\
\text { Rio de Janeiro - } \\
\text { CREMERJ }\end{array}$ & $\begin{array}{c}\text { Imposição da } \\
\text { Classificação Brasileira } \\
\text { Hierarquizada de } \\
\text { Procedimentos Médicos } \\
\text { (CBHPM). }\end{array}$ & $12 / 12 / 2015$ & Condenação \\
\hline 08012.010470/2005-77 & $\begin{array}{c}\text { Ministério Público da } \\
\text { Bahia. }\end{array}$ & $\begin{array}{l}\text { Cooperativa de } \\
\text { Cirurgiões } \\
\text { Cardiovasculares do } \\
\text { Estado da Bahia. }\end{array}$ & $\begin{array}{c}\text { Limitação da } \\
\text { concorrência através de } \\
\text { imposição de tabela de } \\
\text { preços para } \\
\text { procedimentos médicos. }\end{array}$ & $22 / 09 / 2015$ & Condenação \\
\hline
\end{tabular}


Processos Administrativos

\begin{tabular}{|c|c|c|c|c|c|}
\hline \multicolumn{6}{|c|}{ Processos Administrativos } \\
\hline Processo & Representante & Representados & Objeto & Data do julgamento & Decisão \\
\hline 08012.006859/2008-61 & $\begin{array}{c}\text { Unimed Natal - } \\
\text { Cooperativa de Trabalho } \\
\text { Médico. }\end{array}$ & $\begin{array}{c}\text { Clínica de } \\
\text { Neurocirurgiões do Rio } \\
\text { Grande do Norte - } \\
\text { Clineuro. }\end{array}$ & $\begin{array}{l}\text { Influência de prática } \\
\text { concertada entre } \\
\text { neurocirurgiões para } \\
\text { formação de uma } \\
\text { clínica, supostamente } \\
\text { para fixação de preços } \\
\text { em patamares mais } \\
\text { elevados. }\end{array}$ & $22 / 09 / 2015$ & Arquivamento \\
\hline 08012.002706/2009-25 & $\begin{array}{l}\text { Ministério Público } \\
\text { Federal - Procuradoria } \\
\text { da República no Mato } \\
\text { Grosso do Sul. }\end{array}$ & $\begin{array}{l}\text { Servan Anestesiologia e } \\
\text { Tratamento de Dor de } \\
\text { Campo Grande. }\end{array}$ & $\begin{array}{l}\text { Tabela de honorários. } \\
\text { CBHPM. Imposição de } \\
\text { dificuldades à entrada } \\
\text { de novos profissionais. }\end{array}$ & $26 / 08 / 2015$ & Condenação \\
\hline 08012.004276/2004-71 & SDE ex-officio & $\begin{array}{l}\text { Conselho Federal de } \\
\text { Medicina, Associação } \\
\text { Médica Brasileira, } \\
\text { Confederação Médica } \\
\text { Brasileira, Federação } \\
\text { Nacional dos Médicos. }\end{array}$ & $\begin{array}{c}\text { Imposição da } \\
\text { Classificação Brasileira } \\
\text { Hierarquizada de } \\
\text { Procedimentos Médicos } \\
\text { (CBHPM). }\end{array}$ & $04 / 08 / 2015$ & Condenação \\
\hline 08012.010187/2004-64 & AGF Saúde & $\begin{array}{l}\text { Associação Medica de } \\
\text { Pouso Alegre, Corpus } \\
\text { Hospitalar, Hospital e } \\
\text { Clinicas Santa Paula, } \\
\text { Hospital Renascentista } \\
\end{array}$ & $\begin{array}{c}\text { Imposição da } \\
\text { Classificação Brasileira } \\
\text { Hierarquizada de } \\
\text { Procedimentos Médicos } \\
\text { (CBHPM). }\end{array}$ & $04 / 07 / 2015$ & Condenação \\
\hline 08012.000377/2004-73 & $\begin{array}{l}\text { Ministério Público do } \\
\text { Estado da Bahia }\end{array}$ & $\begin{array}{l}\text { Clínica Ortopédica e } \\
\text { Traumatológica Ltda., } \\
\text { Clínica Santa Cecília, } \\
\text { Clínica Sobaby Ltda., } \\
\text { Empreendimentos } \\
\text { Médico-Cirúrgicos }\end{array}$ & $\begin{array}{c}\text { Suposta prática de } \\
\text { conduta concertada com } \\
\text { fins de elevar } \\
\text { artificialmente preços no } \\
\text { mercado de serviços } \\
\text { médicos e hospitalares } \\
\text { em Feira de Santana, }\end{array}$ & $16 / 06 / 2015$ & Condenação \\
\hline
\end{tabular}




\begin{tabular}{|c|c|c|c|c|c|}
\hline \multicolumn{6}{|c|}{ Processos Administrativos } \\
\hline Processo & Representante & Representados & Objeto & Data do julgamento & Decisão \\
\hline & & $\begin{array}{l}\text { Ltda., Hospital e Clínica } \\
\text { São Mateus Ltda. }\end{array}$ & $\begin{array}{c}\text { Bahia. Suposta tentativa } \\
\text { de imposição em bloco } \\
\text { de reajuste de seus } \\
\text { serviços a planos de } \\
\text { saúde. }\end{array}$ & & \\
\hline 08012.006312/2004-31 & $\begin{array}{c}\text { Conselho } \\
\text { Administrativo de } \\
\text { Defesa Econômica. }\end{array}$ & $\begin{array}{l}\text { Cooperativa Brasiliense } \\
\text { dos Anestesiologistas - } \\
\text { COOPANEST- DF. }\end{array}$ & Tabela de preços. & $12 / 05 / 2015$ & Arquivamento \\
\hline 08012.006647/2004-50 & SDE ex-officio & $\begin{array}{c}\text { Conselho Regional de } \\
\text { Medicina de São Paulo, } \\
\text { Associação Paulista de } \\
\text { Medicina e Sindicato } \\
\text { dos Médicos de São } \\
\text { Paulo }\end{array}$ & $\begin{array}{c}\text { Imposição da } \\
\text { Classificação Brasileira } \\
\text { Hierarquizada de } \\
\text { Procedimentos Médicos } \\
\text { (CBHPM). }\end{array}$ & $17 / 03 / 2015$ & Condenação \\
\hline 08012.000432/2005-14 & $\begin{array}{l}\text { Ministério Público de } \\
\text { Minas Gerais - MP/MG. }\end{array}$ & $\begin{array}{l}\text { Associação Médica de } \\
\text { Divinópolis - AMD, } \\
\text { Unimed Divinópolis - } \\
\text { Cooperativa de Trabalho } \\
\text { Médico, Antônio de } \\
\text { Pádua Silva - ex- } \\
\text { presidente da AMD, } \\
\text { Evangelista José Miguel } \\
\text { - Diretor-Presidente da } \\
\text { Unimed Divinópolis. }\end{array}$ & $\begin{array}{c}\text { Imposição da } \\
\text { Classificação Brasileira } \\
\text { Hierarquizada de } \\
\text { Procedimentos Médicos } \\
\text { (CBHPM). }\end{array}$ & $17 / 03 / 2015$ & Condenação \\
\hline 08012.007033/2006-57 & PROCON Londrina PR & $\begin{array}{l}\text { Clínica de Ortopedia e } \\
\text { Traumatologia de } \\
\text { Londrina S/C Ltda., } \\
\text { Hospital do Câncer, } \\
\text { Irmandade Santa Casa }\end{array}$ & $\begin{array}{l}\text { Suposta prática de } \\
\text { conduta concertada. } \\
\text { Suposta tentativa de } \\
\text { imposição em bloco de } \\
\text { reajuste de seus serviços }\end{array}$ & $26 / 11 / 2014$ & Condenação \\
\hline
\end{tabular}




\begin{tabular}{|c|c|c|c|c|c|}
\hline \multicolumn{6}{|c|}{ Processos Administrativos } \\
\hline Processo & Representante & Representados & Objeto & Data do julgamento & Decisão \\
\hline & & $\begin{array}{l}\text { de Londrina, Sociedade } \\
\text { Evangélica Beneficente }\end{array}$ & $\begin{array}{l}\text { à Caixa de Assistência, } \\
\text { Aposentadoria e } \\
\text { Pensões dos Servidores } \\
\text { Municipais de Londrina. }\end{array}$ & & \\
\hline 08012.008551/2013-69 & CADE ex-officio & $\begin{array}{l}\text { Instituto de Medicina, } \\
\text { Cirurgia e Ginecologia e } \\
\text { Hospital Cristo Rei. }\end{array}$ & $\begin{array}{c}\text { Cartel. Negociação } \\
\text { conjunta de valores dos } \\
\text { serviços prestados, } \\
\text { aumentando } \\
\text { indevidamente o poder } \\
\text { de barganha dos } \\
\text { hospitais frente às } \\
\text { operadoras de planos de } \\
\text { saúde. }\end{array}$ & $26 / 11 / 2014$ & Condenação \\
\hline 08012.005101/2004-81 & $\begin{array}{l}\text { SINAMGE - Sindicato } \\
\text { Nacional das Empresas } \\
\text { de Medicina de Grupo }\end{array}$ & $\begin{array}{l}\text { Conselho Regional de } \\
\text { Medicina de Minas } \\
\text { Gerais - CRM/MG, } \\
\text { Associação Médica de } \\
\text { Minas Gerais - } \\
\text { AMMMG, Sindicato } \\
\text { dos Médicos de Minas } \\
\text { Gerais, Federação } \\
\text { Mineira das } \\
\text { Cooperativas Médicas - } \\
\text { FEMCOM }\end{array}$ & $\begin{array}{c}\text { Imposição da } \\
\text { Classificação Brasileira } \\
\text { Hierarquizada de } \\
\text { Procedimentos Médicos } \\
\text { (CBHPM). }\end{array}$ & $12 / 11 / 2014$ & Condenação \\
\hline 08012.001020/2003-21 & $\begin{array}{c}\text { Procon - Campina } \\
\text { Grande }\end{array}$ & \begin{tabular}{|c|} 
Clínica e Pronto Socorro \\
Infantil e Hospital \\
Geral, Clínica Santa \\
Clara, Fundação \\
Assistencial da Paraíba, \\
Hospital Antonio \\
\end{tabular} & $\begin{array}{c}\text { Cartel. Fixação de } \\
\text { preços e condições de } \\
\text { contratos homogêneos. } \\
\text { Boicote. }\end{array}$ & $29 / 10 / 2014$ & Condenação \\
\hline
\end{tabular}




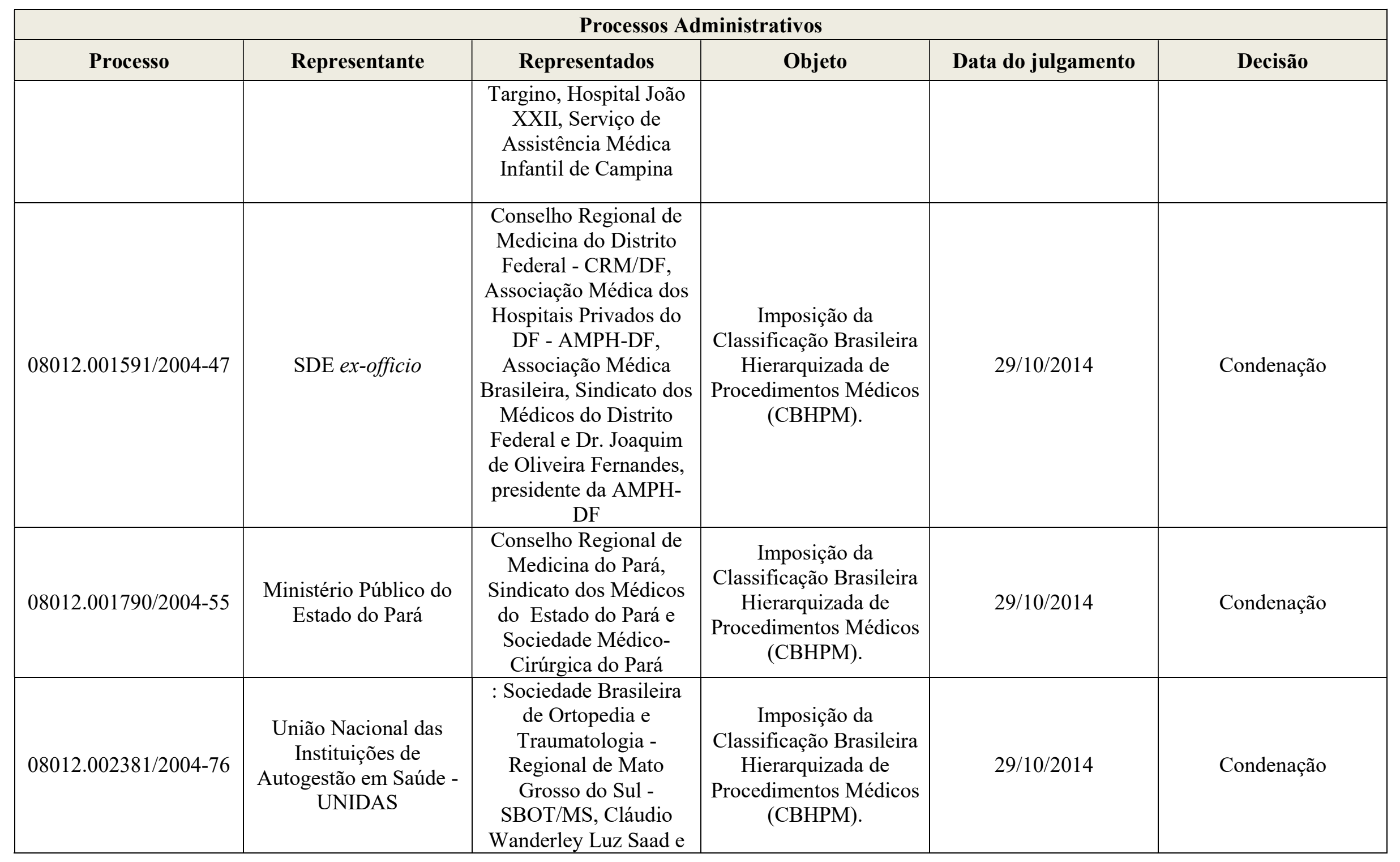




\begin{tabular}{|c|c|c|c|c|c|}
\hline \multicolumn{6}{|c|}{ Processos Administrativos } \\
\hline Processo & Representante & Representados & Objeto & Data do julgamento & Decisão \\
\hline & & $\begin{array}{c}\text { União Nacional das } \\
\text { Instituições de } \\
\text { Autogestão em Saúde - } \\
\text { UNIDAS }\end{array}$ & & & \\
\hline 08012.002985/2004-12 & $\begin{array}{l}\text { Hapvida Assistência } \\
\text { Médica Ltda. }\end{array}$ & $\begin{array}{c}\text { Conselho Regional do } \\
\text { Estado do Maranhão }\end{array}$ & $\begin{array}{c}\text { Imposição da } \\
\text { Classificação Brasileira } \\
\text { Hierarquizada de } \\
\text { Procedimentos Médicos } \\
\text { (CBHPM). }\end{array}$ & $29 / 10 / 2014$ & Condenação \\
\hline 08012.003568/2005-78 & $\begin{array}{c}\text { União Nacional das } \\
\text { Instituições de } \\
\text { Autogestão em Saúde - } \\
\text { UNIDAS }\end{array}$ & $\begin{array}{l}\text { Conselho Regional de } \\
\text { Medicina do Estado de } \\
\text { Roraima }\end{array}$ & $\begin{array}{c}\text { Imposição da } \\
\text { Classificação Brasileira } \\
\text { Hierarquizada de } \\
\text { Procedimentos Médicos } \\
\text { (CBHPM). }\end{array}$ & $29 / 10 / 2014$ & Condenação \\
\hline 08012.003048/2003-01 & $\begin{array}{c}\text { Hapvida Assistência } \\
\text { Médica }\end{array}$ & $\begin{array}{l}\text { Sindicato dos Médicos } \\
\text { do Estado do Ceará; } \\
\text { Conselho Regional de } \\
\text { Medicina do Estado do }\end{array}$ & Tabela de preços. & $15 / 10 / 2014$ & Condenação \\
\hline
\end{tabular}




\begin{tabular}{|c|c|c|c|c|c|}
\hline \multicolumn{6}{|c|}{ Processos Administrativos } \\
\hline Processo & Representante & Representados & Objeto & Data do julgamento & Decisão \\
\hline & & $\begin{array}{l}\text { Ceará e Associação } \\
\text { Médica Cearense }\end{array}$ & & & \\
\hline 08012.004020/2004-64 & $\begin{array}{c}\text { Ministério Público da } \\
\text { Bahia }\end{array}$ & $\begin{array}{l}\text { Conselho Regional de } \\
\text { Medicina da Bahia - } \\
\text { CREMEB }\end{array}$ & $\begin{array}{c}\text { Tabela de honorários } \\
\text { mínimos. Ameaça de } \\
\text { descredenciamento } \\
\text { coletivo. }\end{array}$ & $15 / 10 / 2014$ & Condenação \\
\hline 08012.008477/2004-48 & $\begin{array}{l}\text { Ministério Público do } \\
\text { Estado de Santa } \\
\text { Catarina }\end{array}$ & $\begin{array}{c}\text { Sindicato dos Médicos } \\
\text { do Estado de Santa } \\
\text { Catarina - SIMESC, } \\
\text { Conselho Regional de } \\
\text { Medicina do Estado de } \\
\text { Santa Catarina - } \\
\text { CREMESC, Associação } \\
\text { Catarinense de Medicina } \\
\text { - ACM }\end{array}$ & $\begin{array}{c}\text { Imposição da } \\
\text { Classificação Brasileira } \\
\text { Hierarquizada de } \\
\text { Procedimentos Médicos } \\
\text { (CBHPM). }\end{array}$ & $15 / 10 / 2014$ & Condenação \\
\hline
\end{tabular}




\begin{tabular}{|c|c|c|c|c|c|}
\hline \multicolumn{6}{|c|}{ Processos Administrativos } \\
\hline Processo & Representante & Representados & Objeto & Data do julgamento & Decisão \\
\hline 08012.007833/2006-78 & $\begin{array}{l}\text { Ministério Público } \\
\text { Federal - Procuradoria } \\
\text { da República em } \\
\text { Rondônia }\end{array}$ & $\begin{array}{l}\text { Conselho Regional de } \\
\text { Medicina do Estado de } \\
\text { Rondônia - CREMERO, } \\
\text { Associação Médica de } \\
\text { Rondônia - AMR }\end{array}$ & $\begin{array}{c}\text { Imposição da } \\
\text { Classificação Brasileira } \\
\text { Hierarquizada de } \\
\text { Procedimentos Médicos } \\
\text { (CBHPM). Boicote e } \\
\text { punição. }\end{array}$ & $15 / 10 / 2014$ & Condenação \\
\hline 08012.002866/2011-99 & SDE ex officio & $\begin{array}{c}\text { Conselho Federal de } \\
\text { Medicina, Associação } \\
\text { Médica Brasileira e } \\
\text { Federação Nacional dos } \\
\text { Médicos }\end{array}$ & Tabela médica. Boicote. & $15 / 10 / 2014$ & Condenação \\
\hline 08012.005644/2004-07 & $\begin{array}{l}\text { Ministério Público do } \\
\text { Estado do Espírito Santo }\end{array}$ & $\begin{array}{c}\text { Cooperativa de } \\
\text { Atendimentos Médicos } \\
\text { do Sul do Estado do } \\
\text { Espírito Santo } \\
\text { ("COOPAMESES") }\end{array}$ & $\begin{array}{c}\text { Imposição de } \\
\text { contratação como única } \\
\text { forma de obterem a } \\
\text { prestação de serviços } \\
\text { médicos, principalmente } \\
\text { nas áreas de anestesia, } \\
\text { cirurgia pediátrica, } \\
\text { ortopedia e } \\
\text { neurocirurgia. }\end{array}$ & $19 / 02 / 2014$ & Arquivamento \\
\hline 08012.008739/2007-17 & SDE ex-officio & Unimed de Itabuna & Prática de unimilitância & $19 / 02 / 2014$ & Arquivamento \\
\hline 08012.014463/2007-14 & $\begin{array}{c}\text { Laboratório Atalaia } \\
\text { Ltda. }\end{array}$ & $\begin{array}{l}\text { Unimed Goiânia - } \\
\text { Cooperativa de Trabalho } \\
\text { Médico e Comitê de } \\
\text { Integração das } \\
\text { Entidades de } \\
\text { Representação dos }\end{array}$ & $\begin{array}{l}\text { Denúncia de } \\
\text { descredenciamento em } \\
\text { razão de suposta ação } \\
\text { coordenada promovida } \\
\text { por concorrentes do }\end{array}$ & $22 / 01 / 2014$ & Condenação \\
\hline
\end{tabular}




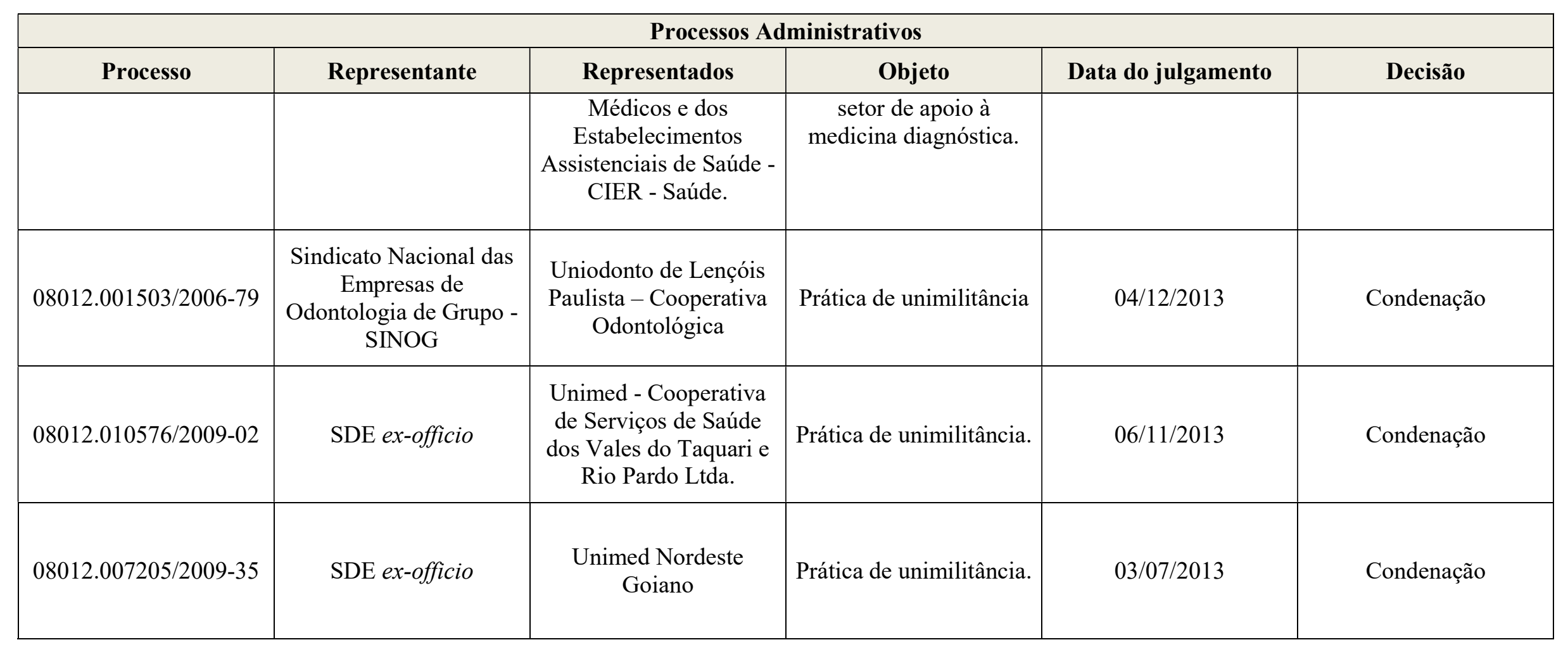

